\title{
A Coordinative Optimization Model for Hydro-Thermal-LNG Power System
}

\author{
Qiang Ding, Jing-yang Zhou, Hui Cui, Dan Xu, \\ Wei-gang Li \\ Power Automation Department \\ China Electric Power Research Institute \\ Beijing, China \\ dingqiang@epri.sgcc.com.cn
}

\author{
Zhi Chen, Yong Deng, Yuzhen Yao, Xin Cheng \\ Dispatch and Communication Center \\ State Grid Fujian Electric Power Company \\ Fuzhou, China
}

\begin{abstract}
This paper proposes a coordinative optimization model based on MILP for Hydro-thermal-LNG power system. The advantage of the method is that it simultaneously solves unit commitment for hydro and LNG( liquefied natural gas) units, and solves economic dispatch for thermal units. The coordinative optimization satisfied all constraints, including unit constraints, operation constraints, water availability constraints and security constraints. It is a global optimization technique for solving generation scheduling problem based on the mixed integer linear programming (MILP) technique. The model is illustrated by example of a provincial network power system. Numerical result based on this practical system shows that the proposed method is efficient and effective for Hydrothermal-LNG power system.
\end{abstract}

Keywords-hydro;thermal;LNG;generation scheduling;model

\section{INTRODUCTION}

Hydro-thermal-LNG power system includes these there types of units: cascaded hydro units, thermal units and liquefied natural gas units. In some province of china, this is a relatively common power source structure. These three kinds of power sources have different operating characteristics, different optimization goals and constraints. Difficulty lies in how to obtain economic and security benefits through co-ordination between these three kinds of power sources.

Researchers have been studying various models to describe the co-ordination between different kinds of units. Mixed integer programming (MILP) [1][3][7] has been used to model the hydro-thermal power system, and quadratic programming [2] model has been built for hydro-thermalnuclear power system. There are also other techniques have been applied to model the hydrothermal generation scheduling problem, such as invasive weed optimization algorithm, evolutionary optimization[4][9][10], genetic algorithm (GA)[5], feedback neural network optimization[6] and simulated annealing embedded evolutionary programming[8]. These models are effective in treating hydro-thermal optimization problem, but when the system has coal-fired units, gas-fired units and hydro units at the same time, each power source should be modeled carefully, and some method can be developed to achieve optimal coordination between these kinds of units, so that the model can be used in the actual production run effectively.
In the proposed coordinative optimization model for hydro-thermal-LNG power system, generation scheduling consists of unit commitment for hydro units and LNG units, which can be startup and shutdown in day time range. And the coal-fired units usually not commit in day time range, because the start-up cost of this kind of unit is relatively high and the minimum up-time/down-time of the unit is typically more than 5 days, so this units usually make unit commitment on a weekly or monthly cycle. In day-ahead generation scheduling, the purpose of the optimization is to make full use of hydro power and minimize costs of coalfired and gas-fired unit, satisfying various constraints. For hydro unit, the objective about penalty function of electric quantity constraints is constructed. For coal-fired units, operation fuel cost is considered. For gas-fired units, operation fuel cost and start-up cost are considered. And all types of units should consider their particular constraints. Through this approach, these three kinds of units can coordinate with each other, to use co-ordination between different power generation characteristics to achieve economic and security benefits.

\section{FLOW DIAGRAM OF THE MODEL}

The unit commitment of coal-fired unit is solved in weekly unit commitment, which can calculate the run-off state of coal-fired unit for day-ahead generation scheduling. So in day-ahead generation scheduling, the model deals with the coordinative optimization problem of unit commitment of hydro and LNG units, and economic dispatch for coalfired units. The hydropower is renewable, so it should be made the best use of. In the proposed model, the electrical quantity of hydro unit should be accommodated firstly, only in some situation, such as coal-fired units are all running in the lower limit, or some transmission constraint only can be controlled by these hydro units, electrical quantity constraints of hydro unit can be modified carefully. So in the model, electrical quantity of hydro unit is considered as soft constraint. The penalty factors are introduced in objective function to make the hydro electric quantity constraints be satisfied under normal situation. The run-off state of coalfired unit has been scheduled in weekly span, so they can be considered as a fixed value in day ahead generation scheduling. The gas-fired unit and hydro unit can be started up or shut down immediately, so they can be used to satisfy reserve constraints and transmission constraints. The 
operation cost of gas-fired unit is more expensive, and the gas storage sets limit to the generation capacity, so in the actual production run, gas-fired units only start up in peak load stage.

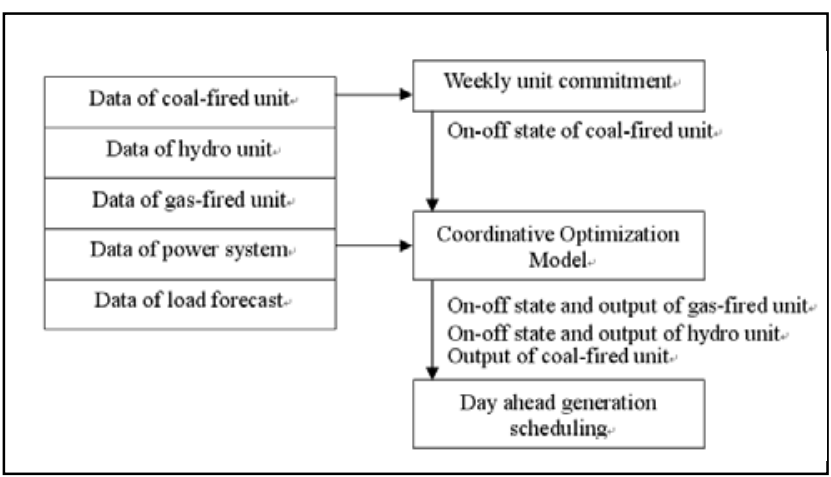

Figure 1. The flow diagram of the proposed model.

In the model depicted in Fig. 1, hydropower can be used firstly within the hydro flow and reservoir storage constraint, then coal-fired units are scheduling to minimize the operation cost and satisfy the open impartial equitable dispatch constraints, and gas-fired units are last considered to peak load shifting, because they can be startup and shutdown in short time but more expensive. These tactics are constructed in a global optimization MILP model, which can be solved by some commercial solver such as CPLEX.

\section{PROPOSED OPTIMIZATION MODEL FOR HYDRO- THERMAL-LNG POWER SYSTEM}

\section{A. Objective Function}

Objective function components are formulated as a model to minimize cost of coal-fired and gas fired units simultaneously, while making full use of hydro power and satisfying various constraints.

Minimize:

$$
\begin{aligned}
F= & \sum_{i=1}^{N_{\text {Coal }}} \sum_{t=1}^{N_{T}} F_{i}\left(P_{i}(t), t\right) \\
& +\sum_{i=1}^{N_{\text {Gas }}} \sum_{t=1}^{N_{T}} F_{i}\left(P_{i}(t), t\right)+\sum_{i=1}^{N_{\text {Gas }}} \sum_{t=1}^{N_{T}} C u_{i}(t) \\
& +\sum_{i=1}^{N_{\text {Hydro }}}\left(\operatorname{Qup}_{i}(t) S P_{\text {up }}+\operatorname{Qdown}_{i}(t) S P_{\text {down }}\right)
\end{aligned}
$$

Where $N_{\text {Hydro }}$ is the number of hydro generation units, $N_{\text {Coal }}$ is the number of coal-fired generation units, and $N_{\text {Gas }}$ is the number of gas fired generation units. $N_{T}$ is the number of periods, $i$ and $t$ are the unit index and period index respectively. $S P_{u p}$ and $S P_{\text {down }}$ are the Up and Down penalty price of hydro electric quantity constraints respectively.
Decision variables: $P_{i}(t)$ is the output of unit $i$ at period $t, C u_{i}(t)$ is the start-up cost of unit $i$ at period $t$, and $\operatorname{Qup}_{i}(t)$ and $Q \operatorname{down}_{i}(t)$ are the Up and Down electric quantity constraints penalty variables of unit $i$ at period $t$, respectively. $C u_{i}(t)$ is the start-up cost of unit $i$.

The cost function of coal-fired and gas-fired units can be expressed as:

$$
\begin{aligned}
& P_{i}(t)=u_{i, 1}(t) \underline{P}_{i}(t)+P_{i, 1}(t)+\sum_{j=2}^{N_{L}}\left(u_{i, j}(t) P_{i, j}^{\text {seg }}(t)+P_{i, j}(t)\right) \\
& \begin{aligned}
F_{i}\left(P_{i}(t), t\right)= & F_{i}\left(\underline{P}_{i}(t), t\right) u_{i, 1}(t)+K_{i, 1}(t) P_{i, 1}(t) \\
& +\sum_{j=2}^{N_{L}}\left(F_{i}\left(P_{i, j}^{\text {seg }}(t), t\right) u_{i, j}(t)+K_{i, j}(t) P_{i, j}(t)\right)
\end{aligned} \\
& \left\{\begin{array}{l}
P_{i, j}(t) \geq 0 \\
P_{i, 1}(t) \leq u_{i, 1}(t)\left(P_{i, 1}^{s e g}(t)-\underline{P}_{i}(t)\right) \\
P_{i, j}(t) \leq u_{i, j}(t)\left(P_{i, j}^{s e g}(t)-P_{i, j-1}^{s e g}(t)\right) \\
\sum_{j=1}^{N_{L}} u_{i, j}(t) \leq 1
\end{array}\right.
\end{aligned}
$$

Where $P_{i, j}^{\text {seg }}(t)$ is the initial output of unit $i$ at segment $j$ of piecewise linear curve, $K_{i, j}(t)$ is slope of unit $i$ at segment $j$ of piecewise linear curve. $N_{L}$ is segment number of piecewise linear curve.

\section{B. Constraints}

The optimization subjects to various constraints as follows:

(1)System power balance constraints:

$\sum_{i=1}^{N_{G}} P_{i}(t)=P_{\text {load }}(t)$

Where $N_{G}$ is the number of all the units in power system, and $P_{\text {load }}(t)$ is system load forecast of period $t$.

(2) Reserve constraints:

$$
\begin{aligned}
& \sum_{i=1}^{N_{G}}\left(\bar{P}_{i}(t) \sum_{j=1}^{N_{L}} u_{i, j}(t)-P_{i}(t)\right) \geq P_{\text {res }}^{u p}(t) \\
& \sum_{i=1}^{N_{G}}\left(P_{i}(t)-\underline{P}_{i}(t) \sum_{j=1}^{N_{L}} u_{i, j}(t)\right) \geq P_{\text {res }}^{\text {down }}(t)
\end{aligned}
$$

Where $P_{\text {res }}^{\text {up }}(t)$ and $P_{\text {res }}^{\text {down }}(t)$ are minimum positive and negative reserve respectively.

(3) Transmission constraints:

$$
\begin{aligned}
& S_{k}^{\text {down }}(t) \leq \sum_{i=1}^{N_{G}}\left(S_{k}\left(\underline{P}_{i}(t), t\right) \sum_{j=1}^{N_{L}} u_{i, j}(t)\right) \leq S_{k}^{\text {up }}(t) \\
& C_{k}^{\text {down }}(t) \leq \sum_{i=1}^{N_{G}}\left(C_{k}\left(\underline{P}_{i}(t), t\right) \sum_{j=1}^{N_{L}} u_{i, j}(t)\right) \leq C_{k}^{u p}(t)
\end{aligned}
$$

Where $S_{k}^{\text {down }}(t)$ and $S_{k}^{u p}(t)$ are minimum and maximum limit of line branch respectively. $C_{k}^{\text {down }}(t)$ and $C_{k}^{u p}(t)$ are minimum and maximum limit of transmission section.

(4) Constraints of all units: 
Unit output limit constraints:

$$
\underline{P}_{i}(t) \sum_{j=1}^{N_{L}} u_{i, j}(t) \leq P_{i}(t) \leq \bar{P}_{i}(t) \sum_{j=1}^{N_{L}} u_{i, j}(t)
$$

Where $\underline{P}_{i}(t)$ and $\bar{P}_{i}(t)$ are minimum and maximum unit limit of unit $i$ at period $t$.

Unit ramping constraints:

$$
\begin{aligned}
& P_{i}(t)-P_{i}(t-1) \leq\left(2-\sum_{j=1}^{N_{L}} u_{i, j}(t)-\sum_{j=1}^{N_{L}} u_{i, j}(t-1)\right) \bar{P}_{i}(t)+P_{i}^{u p}(t) \\
& P_{i}(t-1)-P_{i}(t) \leq\left(2-\sum_{j=1}^{N_{L}} u_{i, j}(t)-\sum_{j=1}^{N_{L}} u_{i, j}(t-1)\right) \bar{P}_{i}(t)+P_{i}^{\text {down }}(t)
\end{aligned}
$$

Where $P_{i}^{u p}(t)$ and $P_{i}^{\text {down }}(t)$ are maximum up and down ramp limit of unit $i$ at period $t$ respectively.

(5) Constraints of gas-fired units:

Curve shape constraints:

$\left.P_{i}(t)=P_{i}(t-1)=P_{i}(t+1)\right), t \in 2,5,8, \ldots$

Minimum on-time/stop-time constraints:

$$
\begin{aligned}
& \sum_{n=t}^{t+T_{\text {mini, }}^{o-1}} \sum_{j=1}^{N_{L}} u_{i, j}(n) \geq T_{\min , i}^{o n}\left(\sum_{j=1}^{N_{L}} u_{i, j}(t)-\sum_{j=1}^{N_{L}} u_{i, j}(t-1)\right) \\
& , u_{i, j} \in u_{\text {gas-fired }} \\
& \sum_{n=t}^{t+T_{\text {off }}^{\text {off }}-1}\left(1-\sum_{j=1}^{N_{L}} u_{i, j}(n)\right) \geq T_{\text {min }, i}^{\text {off }} \text { i }\left(\sum_{j=1}^{N_{L}} u_{i, j}(t-1)-\sum_{j=1}^{N_{L}} u_{i, j}(t)\right) \\
& , u_{i, j} \in u_{\text {gas-fired }}
\end{aligned}
$$

Where $T_{\mathrm{min}, i}^{\text {on }}$ and $T_{\mathrm{min}, i}^{\text {off }}$ are minimum on-time and stoptime of gas-fired unit $i$ at period $t$ respectively.

Gas quantity constraints:

$Q d_{i}<=\sum_{t=1}^{N_{T}} P_{i}(t)<=Q u_{i}$

Where $Q u_{i}$ and $Q d_{i}$ are the electric quantity limit calculating from gas storage of gas-fired unit $i$.

(6) Constraints of coal-fired units:

Pollution emission constraints:

$\sum_{i=1}^{N_{F}}\left(E_{i}\left(\underline{P}_{i}(t), t\right) \sum_{j=1}^{N_{L}} u_{i, j}(t)\right) \leq \operatorname{Er}(t), u_{i, j} \in u_{\text {coal-fired }}$

Where $\operatorname{Er}(t)$ is maximum pollution emission of coalfired units.

Curve shape constraints:

$\left.P_{i}(t)=P_{i}(t-1)=P_{i}(t+1)\right), t \in 2,5,8, \ldots$

(7) Constraints of hydro units:

Curve shape constraints:

$P_{i}(t) \leq \max \left(P_{i}(t-1), P_{i}(t+1)\right)$

and

$P_{i}(t) \geq \min \left(P_{i}(t-1), P_{i}(t+1)\right), t \in 2,3, \ldots N_{T}-1$

Forbidden zones constraints:

The output of hydro unit should avoid to be running in certain regions, resulting in forbidden zones constraints.

$P_{i}(t) \geq$ Pforbidup $_{i, k}$

or

$P_{i}(t) \leq$ Pforbiddown $n_{i, k+1}, k \in 1,2, \ldots N_{D}-1, P_{i} \in P_{\text {hydr }}$
Where Pforbidup $_{i, k}$ and Pforbiddown $n_{i, k+1}$ are the forbidden zones $k$ up and down limit of hydro unit $i$.

\section{CASE StUdy}

Proposed model for hydro-thermal-LNG power system was tested on an example of practical provincial power system. The test system has 300 units, including 180 coalfired units, 90 hydro units and 30 gas-fired units. The optimization of day ahead generation scheduling consider 96 periods. The computation time for solving the model is about 3 minutes.

The model is tested in a platform of HP rx4640 server computer, Itanium 2-1.6 GHz CPU and 16G computer memory. The model was solved by CPLEX12.

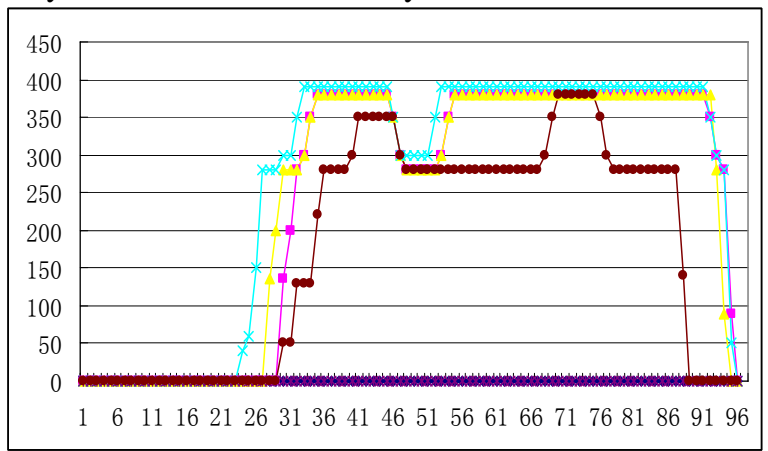

Figure 2. Output curve of some of gas-fired units.

Fig. 2 shows the output curve of some of gas-fired units, it can be seen from the picture that gas-fired units start up about eight o'clock in the morning, when the load of power system increasing rapidly.

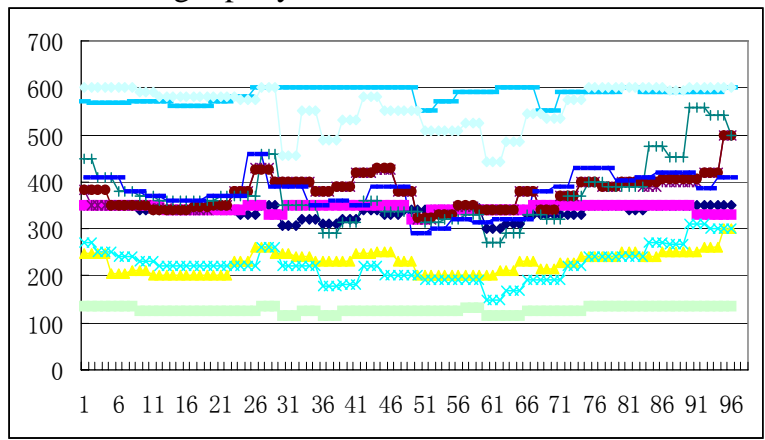

Figure 3. Output curve of some coal-fired units.

Fig. 3 shows the output curve of some of coal-fired units, it can be seen from the picture that the output curve of coalfired units were scheduled smoothly, this can avoid unnecessary adjustment of generation output. 


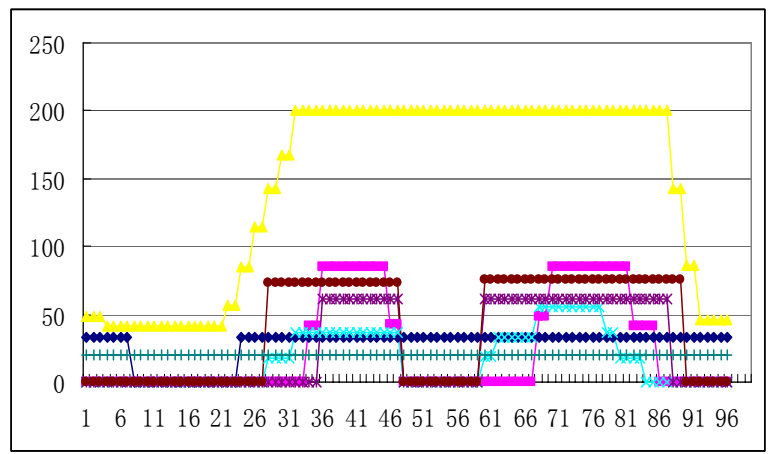

Figure 4. Output curve of some hydro units.

TABLE I. ELECTRICAL QUANTITY OF SOME OF HYDRO UNITS

\begin{tabular}{|l|c|c|}
\hline \multicolumn{3}{|c|}{ Electrical quantity (MW) } \\
\hline & plan & Scheduling \\
\hline Hydro unit 1 & 650 & 650 \\
\hline Hydro unit 2 & 571 & 571 \\
\hline Hydro unit 3 & 3477 & 3477 \\
\hline Hydro unit 4 & 397 & 397 \\
\hline Hydro unit 5 & 615 & 615 \\
\hline Hydro unit 6 & 929 & 929 \\
\hline Hydro unit 7 & 492 & 492 \\
\hline
\end{tabular}

Fig. 4 and Table. 1 show the output curve of some of hydro units, it can be seen that the electrical quantity of hydro units are satisfied after generation scheduling.

\section{CONCLUSION}

(1)This paper proposes a MILP model for coordinative optimization of hydro units, coal-fired units and gas-fired units.

(2)Distinguish from conventional generation scheduling methods, the scheduling model proposed considers operating characteristics of each types of units carefully, constructs each types of units with different objects and constraints.

(3)The objectives of the model include cost of gas-fired units, cost of coal-fired units, start-up cost of gas-fired units and penalty cost of hydro electric quantity constraints.
(4)Meet the complex constraints for each type of units.

(5)Numerical result based on an example of provincial power system shows that the proposed model is efficient and effective for global optimization of units in Hydro-thermalLNG power system.

\section{REFERENCES}

[1] Ding Qiang, Zhou Jing-yang, Pan Yi, Li Qiang, Han Bin, Li Xiao-lei, Guo Xia-ming, Sun Yi, Coordinative Optimization Model Based on MILP for Hydrothermal Power System, Power and Energy Engineering Conference, shanghai, china, 2012

[2] Zhai, Rongrong, Bian, Jing, Yang, Zhiping The Optimization of Power Dispatch for Hydro-thermal Power Systems, 2011 2nd International Conference on Challenges in Environmental Science and Computer Engineering, haikou, china, 2011

[3] Baslis, Costas G, Papadakis, Stylianos E, Bakirtzis, Anastasios G, "Simulation of Optimal Medium-Term Hydro-Thermal System Operation by Grid Computing”, IEEE Transactions on Power Systems, United States, vol. 24, pp. 1208-1217, 2009

[4] Deb, Kalyanmoy, "Scope of stationary multi-objective evolutionary optimization: a case study on a hydro-thermal power dispatch problem”, Journal of Global Optimization, vol.41, pp. 479-515, August 2008

[5] Senthil Kumar, V, Mohan, M.R, “Optimal short-term hydro-thermal scheduling using decomposition approach and GA based OPF", Journal of Electrical Systems, vol. 5, pp.1-14, 2009

[6] Sharma, V., Naresh, R., Sushil, Yadav, Deepika, “Optimal HydroThermal Generation Scheduling Using an Efficient Feedback Neural Network Optimization Model”, Research Journal of Applied Sciences, Engineering and Technology, United Kingdom, vol. 3, pp.770-778, 2011

[7] Aghaei, J., Ahmadi, A, Shayanfar, H.A., Rabiee, A., "Mixed integer programming of generalized hydro-thermal self-scheduling of generating units”, Electrical Engineering, Germany, vol. 95, pp. 109125, June 2013

[8] Asir Rajan, C. Christober, "Hydro-thermal unit commitment problem using simulated annealing embedded evolutionary programming approach”, International Journal of Electrical Power and Energy Systems, United kindom, vol. 33, pp. 939-946, May 2011

[9] Nayak, Nimain Charan;Rajan, C. Christober Asir, "Hydro-Thermal Scheduling by a Hybrid Evolutionary Programming - Simulated Annealing Method in a Large Power System", AIP Conference Proceedings, vol. 1298, pp. 459-466, 2010

[10] Türkay, B, Mecitoglu, F, Baran, S, “Application of a Fast Evolutionary Algorithm to Short-term Hydro-thermal Generation Scheduling”, Energy Sources, Part B: Economics, Planning and Policy, vol. 6, United States, pp. 395-405, Octorber 2011 